\title{
INFLUÊNCIA DAS CARACTERÍSTICAS FÍSICO-QUÍMICAS DO ESGOTO SANITÁRIO NA DESINFECÇÃO COM ÁCIDO PERACÉTICO
}

\author{
Cavallini, G. S..$^{*}$, Campos, S. X. ${ }^{2}$, Souza, J. B. ${ }^{1}$, Vidal, C. M. S. ${ }^{1}$
}

\begin{abstract}
${ }^{1}$ Universidade Estadual do Centro-Oeste UNICENTRO, CP 21 CEP 84.500-000, Irati, PR. *grasiele@irati.unicentro.br ${ }^{2}$ Universidade Estadual de Ponta Grossa UEPG, CEP 84.030-900, Ponta Grossa, PR
\end{abstract}

This paper aimed to study the use of peracetic acid (PAA) to disinfect the wastewater. In this perspective, the consume of PAA and its efficiency to deactivate total coliforms microorganisms and E.coli was investigated and under different conditions of total suspended solids (TSS) and $\mathrm{pH}$. The tests of disinfection with PAA demonstrate that content of TSS over than $50 \mathrm{mg} / \mathrm{L}$ led to an increase of up to $50 \%$ in the consume of disinfectant to the microbial inactivation. The efficiency for inactivation of PAA related to E.coli was also damaged in PH conditions greater than 8. The time of contact had greater influence in the disinfection in dosages up to $5 \mathrm{mg} / \mathrm{L}$ of PAA.

Keywords: Peracetic acid. Disinfection of wastewater. Interfering physical-chemical wastewater.

\section{INTRODUÇÃO}

Os efluentes finais provenientes das Estações de Tratamento de Esgoto (ETE) apresentam elevada densidade de microrganismos indicadores de contaminação fecal (na faixa de $10^{6}-10^{5} \mathrm{NMP} / 100 \mathrm{~mL}$ ). Mesmo após os tratamentos convencionais, com uma eficiência de $90 \%$ de redução de coliformes, ainda não é suficiente para possibilitar que o efluente seja reutilizado para irrigação ou balneabilidade, em que o limite máximo permitido pela Resolução do Conselho Nacional do Meio Ambiente (CONAMA) n ${ }^{\circ} 357 / 11$ para E. coli é de $10^{3}$ $\mathrm{NMP} / 100 \mathrm{~mL}$.

O desinfetante mais utilizado atualmente é o cloro. A grande desvantagem deste desinfetante é a formação de compostos organoclorados, como os trihalometanos, os quais são potencialmente cancerígenos $[1,2,3]$. Neste contexto, justificam-se os estudos de desinfetantes alternativos como o ácido peracético (APA).

No Brasil, a utilização do APA como desinfetante e esterilizante foi concedida pela Agência Nacional de Vigilância Sanitária (ANVISA), em 1993, regulamentando-o como um domissanitários de finalidade antimicrobiana.

O APA é um desinfetante com grande potencial na desinfecção de efluentes, sendo mais amplamente utilizado em países europeus. Os pioneiros a pesquisar o APA como desinfetante no tratamento de efluentes foram Baldry e French [4], os quais descreveram a eficiência do APA relacionando o tempo de contato e a concentração do composto na inativação de bactérias e vírus tipicamente encontrados em esgoto sanitário [5, $6,7,8]$. Posteriormente, outros pesquisadores comprovaram a eficiência do APA mesmo na presença de matéria orgânica $[9,10,11,12,13,14,15]$.

Atualmente a utilização do APA no Brasil é mais comum na área médica e alimentícia para esterilização de equipamentos, entretanto, a sua aplicação na área de saneamento ambiental vem sendo cada vez mais estudada.

O mecanismo de ação do APA na inativação de microrganismos é descrito como um rompimento nas ligações sulfídricas e sulfúricas das enzimas que compõe a membrana celular, prejudicando atividades como: o transporte ativo através da membrana e os níveis de soluto dentro das células [16].

A maior importância da utilização do APA na desinfecção de esgoto é sua propriedade virucida, visto que, em relação ao hipoclorito de sódio a sua capacidade de inativação é menos afetada pela presença de matéria orgânica e permanece em atividade por mais tempo [7]. Quanto à eficiência de inativação de microrganismos o APA apresenta poder bactericida similar ao hipoclorito 
de sódio em relação a coliformes totais, coliformes fecais, E. coli, Salmonella sp. e Pseudomonas sp.

De acordo com suas propriedades físico-químicas, o APA apresenta-se mais eficiente na inativação de bactérias, seguido de vírus, esporos bacterianos e protozoários [17].

O APA é uma mistura quaternária em equilíbrio, formada por ácido peracético, peróxido de hidrogênio, ácido acético e água (reação 1 ).

(reação 1)

$\mathrm{CH}_{3} \mathrm{COOH}+\mathrm{H}_{2} \mathrm{O}_{2}$. $\mathrm{CH}_{3} \mathrm{COOOH}+\mathrm{H}_{2} \mathrm{O}$

O grupo funcional do APA é classificado como ácido percarboxílico. Os perácidos em solução são mais voláteis e menos ácidos do que os ácidos carboxílicos correspondentes. $\mathrm{O} \mathrm{pK}_{\mathrm{a}}$ do ácido peracético é 8,2, enquanto o $\mathrm{pK}_{\mathrm{a}}$ do ácido acético é 4,76. Isto ocorre, porque o perácido tende a formar uma ligação de hidrogênio intramolecular, reduzindo o efeito indutivo do grupo acila sobre o próton devido à introdução de um segundo átomo de oxigênio, como se observa na Figura 1 [18].

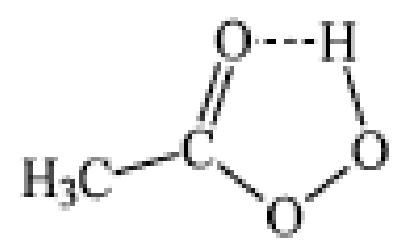

Figura 1 - Possível estrutura do APA (ANDO et al., 1992 [apud 17]).

A eficiência de desinfecção do APA pode variar conforme o tempo de contato, a temperatura, o $\mathrm{pH}$ e o teor de matéria orgânica e de sólidos do efluente [9, 19, 20]. Desta forma, é importante investigar como estes interferentes influenciam na desinfecção, no intuito de prever dosagens adequadas para sua aplicação, ou ainda, a viabilidade da utilização do APA de acordo com as características físico-químicas do efluente.

\section{MATERIAIS E MÉTODOS}

\section{Caracterização do efluente}

Para realização da pesquisa foi utilizado efluente final de uma Estação de Tratamento de Esgoto (ETE) municipal que possui gradeamento, desarenador, dois reatores em paralelo dos tipos UASB e RALF, se- guidos de lagoa facultativa, além de unidade de secagem de lodo.

Os parâmetros selecionados para caracterização do efluente foram: Oxigênio dissolvido, DBO, DQO, Fósforo Total, Nitrogênio Amoniacal, pH, Sólidos, Turbidez, Cor, Cloreto e Microbiológico (Coliformes Totais e E.coli).

As metodologias adotadas para a caracterização do efluente seguiram as descrições do Standard Methods for the Examination of Water and Wastewater (1998). O APA empregado para a realização dos experimentos foi o PROXITANE ${ }^{\circledR} 1512$ doado pela Peróxidos do Brasil.

Ensaios de desinfecção do efluente com APA

Para a desinfecção do efluente com APA foram realizados ensaios variando: tempo de contato (5, 10 e $20 \mathrm{~min})$, dosagem de APA $(1,5,10,15,20,25$ e 30 $\mathrm{mg} / \mathrm{L}$ ), presença e ausência de peróxido de hidrogênio (através da catalase), SST e pH. Em todos esses ensaios a eficiência de desinfecção foi avaliada observando-se a inativação dos microrganismos indicadores de contaminação fecal E. coli e Coliformes totais através do método de membranas filtrantes (nitrato celulose 0,45 $\mu \mathrm{m}$ ) incubadas à $36^{\circ} \mathrm{C}$ em meio de cultura seletivo diferencial e a determinação do APA residual determinado por cerimetria/iodometria.

Para simular diferentes condições de SST do efluente foram utilizadas duas porosidades de membranas: uma com 1,2 $\mu \mathrm{m}$ (Micropore) e outra com $28 \mu \mathrm{m}$ (Quality). A dosagem de APA utilizada foi de $10 \mathrm{mg} / \mathrm{L} \mathrm{e}$ o tempo de contato de 20 minutos.

A eficiência de desinfecção do APA foi testada em 7 faixas de $\mathrm{pH}$ : $4 ; 5 ; 6 ; 7 ; 8 ; 9$ e 10 . Os valores de $\mathrm{pH}$ ácido foram controlados com a adição de ácido sulfúrico (Fmaia) 0,1 mol/L e os valores de pH alcalino através da adição de hidróxido de sódio (Biotec) $0,1 \mathrm{~mol} / \mathrm{L}$.

\section{RESULTADOS E DISCUSSÃO}

\section{O APA na desinfecção de esgoto sanitário}

A caracterização físico-química do esgoto foi realizada para cada coleta e apresentou valores estáveis para todos os parâmetros analisados, exceto para a série de sólidos e cor. Na Tabela 1 são apresentados os valores médios dos parâmetros realizados, fornecendo um diagnóstico geral das condições do esgoto em estudo. 
Tabela 1 - Valores médios dos parâmetros físico-químicos analisados no esgoto.

\begin{tabular}{|c|c|c|}
\hline Parâmetro & Resultado (jy $\pm s d)$ & Método \\
\hline Nitrogênino Amoniacal (mg $/ \mathrm{L})$ & $31 \pm 6$ & Destilação / Titulométrico \\
\hline Fósforo Total (mgL) & $4,2 \pm 0,3$ & Espectrofotométrico (Vis) \\
\hline $\mathrm{ST}(\mathrm{mg} \mathrm{L})$ & $361 \pm 76$ & Gravimétrico \\
\hline SDT (mgL) & $347 \pm 49$ & Filtração / Gravimétrico \\
\hline SST (mgL) & $54 \pm 29$ & Filtração / Gravimétrico \\
\hline Alcalinidade (mg de $\mathrm{CaCO}_{3}[\mathrm{~L})$ & $44 \pm 9$ & Titulométrico \\
\hline Turbidez (NTU) & $22 \pm 4$ & Nefelométrico \\
\hline Cor Aparente (UC) & $476 \pm 54$ & Espectrofotométrico (Vis) \\
\hline Cor Verdadeira $(\mathrm{UC})$ & $212 \pm 8$ & Centrifugação / Espectrofotométrico (Vis) \\
\hline $\mathrm{pH}$ & $7,6 \pm 0,15$ & Potenciométrico \\
\hline $\mathrm{DQO}(\mathrm{mg} \mathrm{L})$ & $131 \pm 37$ & Espectrofotométrico (Vis) \\
\hline $\mathrm{DBO}$ (mg & $22 \pm 3$ & Oximétrico \\
\hline E. coli (UFC/100mL) & $10^{5}$ & Membranas Filtrantes \\
\hline Coliformes Totais (UFC/100mL) & $10^{6}$ & Membranas Filtrantes \\
\hline Cloreto (mgL) & 173 & Titulométrico \\
\hline $\mathrm{OD}(\mathrm{mg} \mathrm{L})$ & $4,1=0,5$ & Oximétrico \\
\hline
\end{tabular}

$\bar{j}=$ média aritmética; $s d=$ destio padrão.

A análise preliminar da eficiência do APA na desinfecção foi realizada utilizando três diferentes dosagens de APA, cada uma delas em três tempos de contato 5,10 e 20 minutos.

A Figura 2 demonstra de forma comparativa as diferentes dosagens aplicadas, nos tempos de contato e os respectivos resultados de inativação obtidos de acordo com a equação $\log \mathrm{N} / \mathrm{N}_{0}$, em que $\mathrm{N}_{0}$ é o número inicial de microrganismos antes da desinfecção e $\mathrm{N}$ é o número final de microrganismos após a desinfecção, considerando o esgoto com $\mathrm{pH}=7,57$; turbidez $=23,8$ $\mathrm{uT}$ e SST= $54 \mathrm{mg} / \mathrm{L}$.

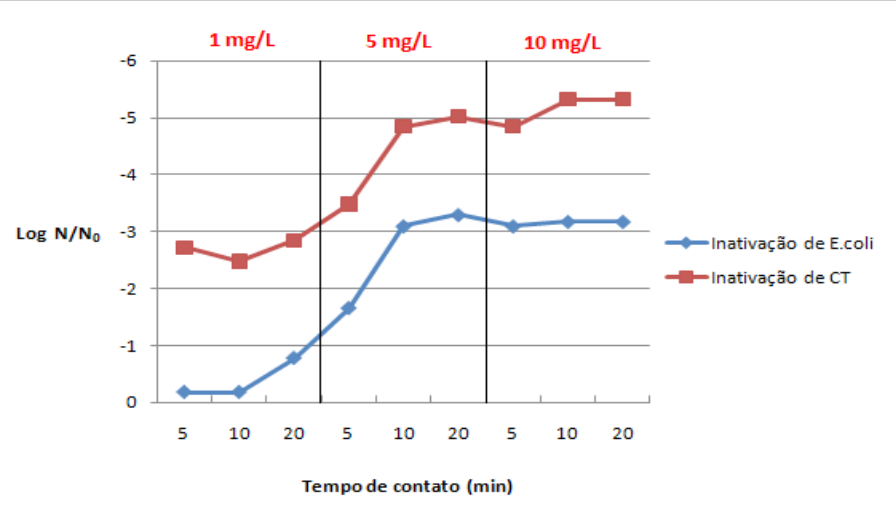

Figura 2 - Desinfecção com APA variando dosagens e tempos de contato.
De acordo com os resultados obtidos, dosagens superiores a $1 \mathrm{mg} / \mathrm{L}$ de APA são necessárias para inativação de E. coli, contudo, nesta dosagem a inativação de coliformes totais (CT) já é iniciada.

Outros pesquisadores observaram a inativação de 2 logs de E. coli com aplicação de $2 \mathrm{mg} / \mathrm{L}$ de APA por 20 minutos, em esgoto sanitário secundário [20]. Enquanto Morris (1993) [apud 4] indicou $5 \mathrm{mg} / \mathrm{L}$ de APA e tempo de contato de 20 minutos para inativação de 4 a 5 logs de coliformes totais na desinfecção de esgoto sanitário secundário.

$\mathrm{Na}$ Figura 2 verificou-se que a partir do tempo de contato de 10 minutos com a dosagem de $5 \mathrm{mg} / \mathrm{L} \mathrm{de}$ APA foi possível atingir a mesma ordem logarítmica de inativação, tanto de E. coli quanto de $\mathrm{CT}$, que na maior dosagem empregada de $10 \mathrm{mg} / \mathrm{L}$. O aumento do tempo de contato na dosagem de $10 \mathrm{mg} / \mathrm{L}$ não contribuiu para a melhoria da eficiência de inativação dos microrganismos, com isso, pode-se observar que o tempo de contato não interferiu significativamente na desinfecção do esgoto quando as concentrações do desinfetante eram maiores que as necessárias para a desinfecção.

A partir das concentrações residuais de APA obtidas pelas aplicações das dosagens de 5 e $10 \mathrm{mg} / \mathrm{L}$ foi possível observar que a inativação dos microrganismos não é limitada apenas pelo consumo completo do desinfetante, visto que, a inativação cessou mesmo havendo APA disponível no esgoto. Ensaios com dosagens mais elevadas de APA foram realizados (Figura 3 ) com efluente apresentando: $\mathrm{pH}=7,38$; turbidez $=26,9 \mathrm{uT}, \mathrm{SST}=$ $56 \mathrm{mg} / \mathrm{L}$ e ST= $474 \mathrm{mg} / \mathrm{L}$.

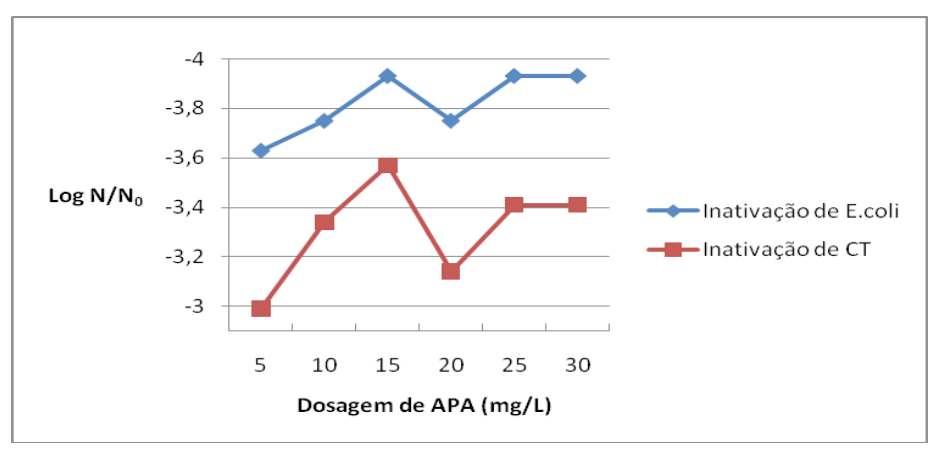

Figura 3 - Inativação de E. coli e CT conforme a dosagem de APA.

Os resultados apresentados na Figura 3 são referentes aos ensaios realizados com tempo de contato fixo de 20 minutos. Este tempo pode ser indicado para desinfecção de esgoto sanitário com dióxido de cloro, 
sendo assim, as mesmas dimensões do tanque de contato poderiam ser utilizadas tanto para o cloro como para o APA em casos de aplicação do APA em escala plena numa ETE [21, 23].

Embora tempos de contato de 5 e 10 minutos já sejam suficientes para dosagens acima de $5 \mathrm{mg} / \mathrm{L}$, as condições estruturais devem ser consideradas, desta forma tanques já existentes podem ser utilizados diminuindo os custos para implantação do APA como desinfetante.

Quanto aos resultados obtidos as dosagens de 5 a $30 \mathrm{mg} / \mathrm{L}$ permitiram a mesma ordem logarítmica de inativação, com variação inferior a $0,3 \log$ na inativação de E. coli e de 0,6 log na inativação de CT. Esta variação pode ser atribuída às dosagens aplicadas, como também à variação populacional da amostra, visto que variações nestas proporções são observadas em ensaios de repetição, onde a variação ocorre mesmo em condições de dosagem, tempo de contato e efluentes iguais.

$\mathrm{Na}$ dosagem de $10 \mathrm{mg} / \mathrm{L}$ de APA a inativação de E. coli foi de aproximadamente 3 logs.

Na Tabela 2 são apresentados os valores consumidos de APA e peróxido de hidrogênio durante os ensaios de desinfecção demonstrados na Figura 3. Com estes resultados é possível avaliar que um valor médio de consumo de APA pode ser calculado, ou seja, o consumo de APA demonstrou uma relação maior com as condições do efluente do que com sua concentração inicial, ao contrário do ocorrido com o peróxido de hidrogênio.

Tabela 2 - Consumo de APA e Peróxido de Hidrogênio durante a desinfecção.

\section{Participação do Peróxido de Hidrogênio na} desinfecção com APA

Considerando que tanto o peróxido de hidrogênio quanto o APA apresentam propriedades desinfetantes, o efeito da eficiência individual ou em conjunto dessas substâncias torna-se importante. Alguns autores [24] levantam a hipótese de que o peróxido de hidrogênio contribui adicionalmente na eficiência de desinfecção com APA, porém, não realizaram ensaios que comprovassem este sinergismo.

A fim de investigar este efeito, a inativação de microrganismos foi avaliada na presença e na ausência do peróxido de hidrogênio, utilizando a catalase como inibidora deste oxidante.

Na Tabela 3 são apresentados os resultados obtidos para verificação da participação do peróxido de hidrogênio na desinfecção com APA em duas condições diferentes de SST do esgoto.

De acordo com os resultados obtidos a participação do peróxido de hidrogênio não contribuiu significativamente na eficiência de inativação dos microrganismos, visto que a pequena variação nos logs de remoção pode ser considerada como uma variação amostral.

Em comparação com o resultado obtido por outro autor [22] $12 \mathrm{mg} / \mathrm{L}$ de APA ou $3125 \mathrm{mg} / \mathrm{L}$ de peróxido de hidrogênio apresentaram a mesma eficiência de inativação bacteriana. Quando utilizados de forma combinada a mesma eficiência de inativação foi obtida com $3 \mathrm{mg} / \mathrm{L}$ de APA e $390 \mathrm{mg} / \mathrm{L}$ de peróxido de hidrogênio. Portanto, o sinergismo entre os oxidantes ocorreu em proporções de peróxido de hidrogênio 130 vezes maior que a concentração do APA [22].

\begin{tabular}{c|c|c|c|c|c|c|c}
\hline \multicolumn{9}{c|}{ Ensaio 1 (SST 38 mg/L) } & \multicolumn{4}{c}{ Ensaio 2 (SST 28 mg/L) } \\
\hline $\begin{array}{c}{[\mathrm{APA}]_{0}} \\
(\mathrm{mg} / \mathrm{L})\end{array}$ & $\begin{array}{c}{\left[\mathrm{H}_{2} \mathrm{O}_{2}\right]} \\
(\mathrm{mg} / \mathrm{L})\end{array}$ & $\begin{array}{c}E . \text { coli } \\
(\mathrm{UFC} / 100 \mathrm{~mL})\end{array}$ & $\begin{array}{c}\mathrm{CT} \\
(\mathrm{UFC} / 100 \mathrm{~mL})\end{array}$ & $\begin{array}{c}[\mathrm{APA}]]_{0} \\
(\mathrm{mg} / \mathrm{L})\end{array}$ & $\begin{array}{c}{\left[\mathrm{H}_{2} \mathrm{O}_{2}\right] 0} \\
(\mathrm{mg} / \mathrm{L})\end{array}$ & $\begin{array}{c}E . \text { coli } \\
(\mathrm{UFC} / 100 \mathrm{~mL})\end{array}$ & $\begin{array}{c}\mathrm{CT} \\
(\mathrm{UFC} / 100 \mathrm{~mL})\end{array}$ \\
\hline 0 & 0 & $1.10^{5}$ & $1,7.10^{6}$ & 0 & 0 & $2,3.10^{5}$ & $3,9.10^{6}$ \\
\hline 10 & 0 & $1.10^{1}$ & $3.10^{2}$ & 10 & 0 & $<1$ & $2,8.10^{3}$ \\
\hline 10 & 15,4 & $2.10^{1}$ & $4.10^{2}$ & 10 & 15,4 & $<1$ & $1,2.10^{3}$ \\
\hline
\end{tabular}

Das dosagens utilizadas selecionou-se a dosagem de $10 \mathrm{mg} / \mathrm{L}$ de APA e o tempo de contato de 20 minutos para prosseguir com os estudos de desinfecção. Esta dosagem foi selecionada para garantir que o APA estivesse em uma concentração suficiente mesmo que o esgoto apresentasse condições físico-químicas e microbiológicas que requeressem maiores doses de desinfetante.
Com isso contata-se que embora o sinergismo entre o APA e o peróxido de hidrogênio exista, a proporção das dosagens em estudo não é suficiente para desencadeá-lo entre os desinfetantes, atribuindo-se totalmente ao APA as eficiências de inativação obtidas nesse estudo.

A Influência dos SST na desinfecção com APA 
Tabela 3 - Estudo da participação do peróxido de hidrogênio na desinfecção com APA em um tempo de contato de 20 minutos. fenômenos dependentes do tipo de partícula sólida e da associação entre o material em suspensão e o microrganismo.

\begin{tabular}{c|c|c|c|c|c|c|c}
\hline \multicolumn{4}{c|}{ Ensaio 1 ( SST 38 mg/L) } & \multicolumn{4}{c}{ Ensaio 2 (SST 28 mg/L) } \\
\hline $\begin{array}{c}{[\mathrm{APA}]_{0}} \\
(\mathrm{mg} / \mathrm{L})\end{array}$ & $\begin{array}{c}{\left[\mathrm{H}_{2} \mathrm{O}_{2}\right] \mathrm{0}} \\
(\mathrm{mg} / \mathrm{L})\end{array}$ & $\begin{array}{c}E . \text { coli } \\
(\mathrm{UFC} / 100 \mathrm{~mL})\end{array}$ & $\begin{array}{c}\mathrm{CT} \\
(\mathrm{UFC} / 100 \mathrm{~mL})\end{array}$ & $\begin{array}{c}{[\mathrm{APA}]_{0}} \\
(\mathrm{mg} / \mathrm{L})\end{array}$ & $\begin{array}{c}{\left[\mathrm{H}_{2} \mathrm{O}_{2}\right] 0} \\
(\mathrm{mg} / \mathrm{L})\end{array}$ & $\begin{array}{c}E . \text { coli } \\
(\mathrm{UFC} / 100 \mathrm{~mL})\end{array}$ & $\begin{array}{c}\mathrm{CT} \\
(\mathrm{UFC} / 100 \mathrm{~mL})\end{array}$ \\
\hline 0 & 0 & $1.10^{5}$ & $1,7.10^{6}$ & 0 & 0 & $2,3.10^{5}$ & $3,9.10^{6}$ \\
\hline 10 & 0 & $1.10^{1}$ & $3.10^{2}$ & 10 & 0 & $<1$ & $2,8.10^{3}$ \\
\hline 10 & 15,4 & $2.10^{1}$ & $4.10^{2}$ & 10 & 15,4 & $<1$ & $1,2.10^{3}$ \\
\hline
\end{tabular}

As bactérias coliformes podem estar presentes no esgoto de duas formas: associadas ao material particulado ou dispersas na solução. O APA pode ser aplicado em efluentes com valores de SST até $100 \mathrm{mg} / \mathrm{L}$ [9]. Isto porque, o aumento dos sólidos colabora para que a maior parte das bactérias esteja associada ao material particulado no efluente, contribuindo para o aumento da demanda do desinfetante e diminuição da eficiência de inativação dos microrganismos, por estes estarem protegidos pelos sólidos suspensos $[9,19,20]$.

Este comportamento pôde ser observado na desinfecção com APA comparando diferentes condições de SST no esgoto. A Tabela 4 demonstra que, com o aumento dos SST ocorreu tanto o decréscimo da eficiência do APA como o maior consumo do desinfetante, sendo que, em condições de SST superiores a $50 \mathrm{mg} / \mathrm{L}$ o consumo de APA foi 50\% maior.
No presente estudo, nas condições de SST mais baixos a eficiência de inativação do APA foi maior em relação a E. coli do que em relação a CT, e a Figura 4 representa isto considerando os logs de inativação tanto de E. coli como de CT.

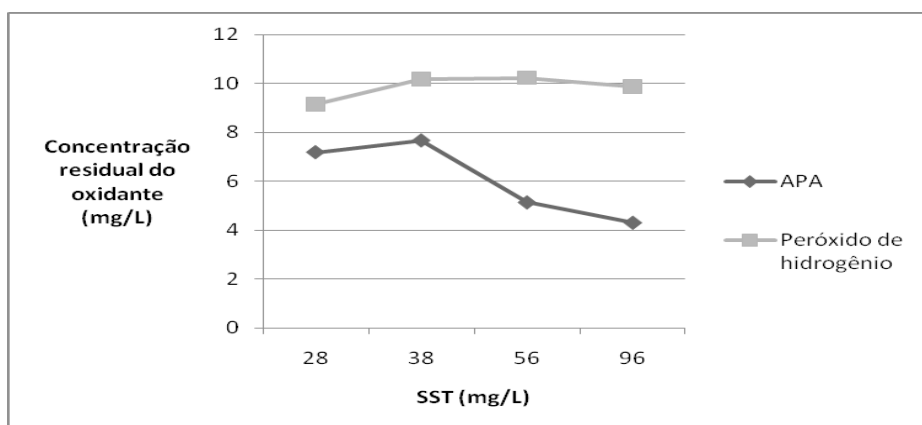

Figura 4 - Eficiência de desinfecção do APA em condições variáveis de SST.

Tabela 4 - Influência do SST na desinfecção e no consumo de APA.

\begin{tabular}{c|c|c|c|c|c|c}
\hline \multirow{2}{*}{$\begin{array}{c}\text { SST } \\
(\mathbf{m g} / \mathbf{L})\end{array}$} & \multicolumn{2}{|c|}{ Sem APA } & $\begin{array}{c}\text { APA (10 mg/L)/H } \\
\text { (Tempo de contato 20 min) }\end{array}$ & \multicolumn{2}{c}{ Residual } \\
\cline { 2 - 7 } & $\begin{array}{c}\text { E. coli } \\
\text { (UFC/100mL) }\end{array}$ & $\begin{array}{c}\text { CT } \\
\text { (UFC/100mL) }\end{array}$ & $\begin{array}{c}\text { E. coli } \\
\text { (UFC/100mL) }\end{array}$ & $\begin{array}{c}\text { CT } \\
(\text { UFC/100mL) }\end{array}$ & $\begin{array}{c}{[\mathbf{A P A}]} \\
(\mathbf{m g} / \mathbf{L})\end{array}$ & $\begin{array}{c}{\left[\mathbf{H}_{2} \mathbf{O}_{2}\right]} \\
(\mathbf{m g} / \mathbf{L})\end{array}$ \\
\hline 28 & $2,3.10^{5}$ & $3,9.10^{6}$ & $<1$ & $1,2.10^{3}$ & 7,18 & 9,15 \\
\hline 38 & $1.10^{5}$ & $1,7.10^{6}$ & $2.10^{1}$ & $4.10^{2}$ & 7,66 & 10,17 \\
\hline 56 & $1,7.10^{6}$ & $5,2.10^{6}$ & $3.10^{2}$ & $2,4.10^{3}$ & 5,13 & 10,23 \\
\hline 96 & $5.10^{4}$ & $2,3.10^{6}$ & $1.10^{2}$ & $1,5.10^{3}$ & 4,30 & 9,87 \\
\hline
\end{tabular}

De acordo com outros trabalhos a presença de SST até $10 \mathrm{mg} / \mathrm{L}$ aumenta a demanda de APA na inativação de microrganismos e, a partir de 10 até $40 \mathrm{mg} / \mathrm{L}$ de sólidos em suspensão, mesmo com o aumento do oxidante não há acréscimo da eficiência de inativação microbiana [19].

No entanto, outros autores não observaram esta influência dos SST na desinfecção de esgoto sanitário tanto com APA nas concentrações aplicadas de 5, 10 e $15 \mathrm{mg} / \mathrm{L}$ com SST entre 43 e $107 \mathrm{mg} / \mathrm{L}$ [11] como com SST médio de $17 \mathrm{mg} / \mathrm{L}$, utilizando dosagens próximas de $2 \mathrm{mg} / \mathrm{L}$ de APA [25].

Sobsey (1989) [apud 11] justifica esta variação da influência ou não dos SST na desinfecção como
Para descrever a associação das bactérias coliformes no material particulado foram realizados ensaios com duas porosidades micrométricas de membrana, conforme a Tabela 5. 
Tabela 5 - Ensaios de desinfecção com efluente filtrado.

\begin{tabular}{l|c|c|c|c}
\hline & \multicolumn{2}{|c|}{ Sem APA } & \multicolumn{2}{c}{$10 \mathrm{mg} / \mathrm{L}$ de APA (20 min) } \\
\hline & $\begin{array}{c}E . \text { coli } \\
(\mathrm{UFC} / 100 \mathrm{~mL})\end{array}$ & $\begin{array}{c}\text { CT } \\
(\mathrm{UFC} / 100 \mathrm{~mL})\end{array}$ & $\begin{array}{c}E . \text { coli } \\
(\mathrm{UFC} / 100 \mathrm{~mL})\end{array}$ & $\begin{array}{c}\text { CT } \\
(\mathrm{UFC} / 100 \mathrm{~mL})\end{array}$ \\
\hline Efluente Bruto - SST $96 \mathrm{mg} / \mathrm{L}$ & $5.10^{4}$ & $2,3.10^{6}$ & $1.10^{2}$ & $1,5.10^{3}$ \\
\hline Filtrado (membrana $28 \mu \mathrm{m})-\mathrm{SST} 20 \mathrm{mg} / \mathrm{L}$ & $7,9.10^{4}$ & $2.10^{5}$ & $1,3.10^{2}$ & $4,4.10^{2}$ \\
\hline Filtrado (membrana $1,2 \mu \mathrm{m})-\mathrm{SST}<0,1 \mathrm{mg} / \mathrm{L}$ & $2,3.10^{3}$ & $8,6.10^{3}$ & 1 & $1,1.10^{1}$ \\
\hline
\end{tabular}

Com a membrana de $28 \mu \mathrm{m}$ é possível avaliar a quantidade de microrganismo protegidos por partículas relativamente grandes. Nesta amostra, apenas os coliformes totais estavam associados a estas partículas maiores, correspondendo a $91 \%$ da população de CT.

Para os padrões de qualidade da água os sólidos suspensos correspondem ao material particulado retido em membrana de $1,2 \mu \mathrm{m}[26,27,28]$. A partir desta filtração é possível estimar o número de microrganismos associados ao material particulado.

De acordo com a Tabela 5 observou-se que nesta amostra $95,4 \%$ da população de E.coli está no material particulado, assim como $99,6 \%$ dos coliformes totais.

No entanto, mesmo com a retirada dos SST a desinfecção com APA não foi total, obtendo-se apenas um aumento na inativação de ambos os indicadores de contaminação.

Embora estes ensaios confirmem a influência dos SST na desinfecção com APA, evidenciou-se também que este não é o único fator que interfere na eficiência de inativação do desinfetante, o que levou a questionar outras características físico-químicas do esgoto, como o $\mathrm{pH}$.
A influência do pH na desinfecção com APA

O estudo da influência do $\mathrm{pH}$ na desinfecção do esgoto com APA teve como propósito encontrar uma faixa de $\mathrm{pH}$ onde a desinfecção fosse mais efetiva. De acordo com os dados apresentados na Tabela 6 pode-se observar o comportamento do APA em cada faixa de pH estudada e sua eficiência de inativação correspondente.

As maiores concentrações de APA residual ocorreram nos ensaios com $\mathrm{pH}$ abaixo de 7,0, em que o ácido sulfúrico foi adicionado, isto porque a adição do ácido sulfúrico catalisa o equilíbrio entre a mistura: ácido acético, peróxido de hidrogênio e APA, impedindo sua decomposição [29, 30, 31]. A ausência do ácido sulfúrico nas faixas de $\mathrm{pH}$ alcalino contribui para a decomposição do APA e por isso os resultados referentes a concentração de APA residual foram menores.

Além disso, o APA em pH alcalino se encontra principalmente na forma dissociada, não ativa, visto que seu $\mathrm{pK}_{\mathrm{a}}$ é de 8,2 [9], o que é evidenciado pelo decréscimo nas concentrações de APA residual conforme o aumento do $\mathrm{pH}$.

Tabela 6 - Influência do pH na desinfecção com APA.

\begin{tabular}{c|c|c|c|c|c|c}
\hline \multicolumn{4}{|c|}{ Sem APA } & \multicolumn{4}{c}{$10 \mathrm{mg} / \mathrm{L}$ de APA -20 minutos } \\
\hline $\mathrm{pH}$ & $\begin{array}{c}E . \text { coli } \\
(\mathrm{UFC} / 100 \mathrm{~mL})\end{array}$ & $\begin{array}{c}\mathrm{CT} \\
(\mathrm{UFC} / 100 \mathrm{~mL})\end{array}$ & $\begin{array}{c}E . \text { coli } \\
(\mathrm{UFC} / 10 \mathrm{~mL})\end{array}$ & $\begin{array}{c}\mathrm{CT} \\
(\mathrm{UFC} / 100 \mathrm{~mL})\end{array}$ & $\begin{array}{c}\text { Residual } \\
\mathrm{H}_{2} \mathrm{O}_{2}(\mathrm{mg} / \mathrm{L})\end{array}$ & $\begin{array}{c}\text { Residual } \\
\text { APA (mg/L) }\end{array}$ \\
\hline 7,75 (Bruto) & $7.10^{4}$ & $6.10^{5}$ & - & - & - & - \\
\hline 4 & $4.10^{5}$ & $6.10^{5}$ & 2 & $1.10^{3}$ & 11,92 & 7,25 \\
\hline 5 & $4.10^{5}$ & $6.10^{5}$ & $<1$ & $5.10^{2}$ & 10,89 & 6,84 \\
\hline 6 & $4.10^{5}$ & $6.10^{5}$ & $<1$ & $7.10^{2}$ & 10,29 & 7,18 \\
\hline 7 & $4.10^{5}$ & $6.10^{5}$ & $<1$ & $8.10^{2}$ & 9,27 & 7,18 \\
\hline 8 & $7,4.10^{4}$ & $3,1.10^{5}$ & 4 & $8.10^{2}$ & 9,15 & 6,70 \\
\hline 9 & $6,7.10^{3}$ & $2,9.10^{5}$ & $3.10^{1}$ & $1,4.10^{3}$ & 7,34 & 5,13 \\
\hline 10 & $5,4.10^{3}$ & $2,6.10^{5}$ & $7.10^{3}$ & $1,6.10^{4}$ & 5,96 & 5,13 \\
\hline
\end{tabular}

Características do esgoto: Turbidez $=16,8 \mathrm{uT} ; \mathrm{SST}=28 \mathrm{mg} / \mathrm{L} ; \mathrm{ST}=306 \mathrm{mg} / \mathrm{L} ;$ Alcalinidade $=38 \mathrm{mg} / \mathrm{L}$. 
É possível observar ainda, de acordo com os dados apresentados na Tabela 6 , que a inativação microbiana foi afetada pelo $\mathrm{pH}$ mesmo sem a adição do APA, isto porque, existem faixas de tolerâncias de $\mathrm{pH}$ específicas, para o cultivo, crescimento e sobrevivência para cada grupo de microrganismos, sendo por exemplo, a faixa de $\mathrm{pH}$ ótimo de crescimento de E. coli situada entre 6,0 e 7,0 com faixa de tolerância entre 4,4 e 8,5.

De acordo com os resultados obtidos constatou-se que embora a eficiência do APA tenha sido melhor em $\mathrm{pH} 5$, a acidificação do esgoto em estudo não colaborou de forma significativa para a desinfecção com APA. Nesse sentido, em situações de escala real, a desinfecção pode ser realizada no $\mathrm{pH}$ natural do esgoto e a acidificação só é indicada em casos de faixas de $\mathrm{pH}$ de esgoto acima de 9 , o que não é comum de ser verificado em esgoto sanitário tratado.

\section{CONCLUSÕES}

Através dos estudos realizados neste trabalho observou-se que para os ensaios de desinfecção com APA o tempo de contato contribui para inativação de microrganismos E. coli e CT em dosagens até $5 \mathrm{mg} / \mathrm{L}$. A eficiência de desinfecção do APA na inativação destes microrganismos não apresentou-se unicamente dependente da dosagem aplicada, uma vez que a diminuição dos SST do esgoto e as condições de $\mathrm{pH}$ ácido à neutro contribuíram para a eficiência deste desinfetante. No entanto, a não inativação total dos microrganismos mesmo com a remoção dos SST dá indícios de que partículas coloidais menores que $1,2 \mu \mathrm{m}$ podem proteger os microrganismos. A presença do peróxido de hidrogênio na composição do APA não apresentou contribuição na sua eficiência desinfetante, excluindo a possibilidade de sinergismo entre os oxidantes nas proporções apresentadas pelo APA 15\% comercial. De forma geral, percebe-se que a eficiência de desinfecção do APA em esgoto sanitário pode ser limitada pelas características físico-químicas do efluente, o que faz com que erroneamente dosagens excessivas de desinfetante sejam utilizadas sem reais contribuições, justificando a investigação e identificação destes interferentes.

\section{REFERÊNCIAS BIBLIOGRÁFICAS}

[1] P. C., SINGER, Wat. Sci. Tech. 40 (9) (1999) 25.

[2] E. VESCHETTI, D. CUTILLI, L. BONADONNA,
R. BRIANCESCO, C. MARTINI, G, CECCHINI, P. ANASTASI, M. OTTAVIANI, Water Res. 37 (2003) 78. [3] R. DUMITRU, U. VON GUNTEN, A. MOCAN, R. CHIRA, B. SIEGFRIED, M. H.KOVACS, S. VANCEA, Environ. Sci. Pollut. Res.16 (2009) 55.

[4] M. KITIS, Environ. Int. 30 (2004) 47.

[5] M. G. C. BALDRY, M. S. FRENCH, Wat. Sci. Tech. 21 (3) (1989a) 203.

[6] M. G. C. BALDRY, M. S. FRENCH, Wat. Sci. Tech. 21, (1989b) 1747.

[7] M. G. C. BALDRY, M. S. FRENCH, D. SLATER, Wat. Sci. Tech. 24 (2) (1991) 353.

[8] M. G. C. BALDRY,A. CAVADORE, M. S. FRENCH, G. MASSA, L. M. RODRIGUES, P. F.T. SCHIRCH, T. L. THREADGOLD, Wat. Sci. Tech. 31(5-6) (1995) 161.

[9] C. SANCHEZ-RUIZ, S. MARTINEZ-ROYANO, I. TEJERO-MONZON, Wat. Sci Tech. 32 (7) (1995) 159. [10] R. L. RAJALA-MUSTONEN, P. S. TOIVOLA, H. HEINONEN-TANSKI, Wat. Sci. Tech. 35 (11) (1997) 237.

[11] L. SARTORI, Tese (Dourado) Escola de Engenharia de São Carlos (2004) 202.

[12] J. KOIVUNEN, H. HEINONEN-TANSKI, Water Res. 39 (2005) 4445.

[13] D. FALSANISI, R GEHR, D. SANTORO, A. DELL'ERBA, M. NOTARNICOLA, L. LIBERTI, Water Qual. Res. J. Can. 41(4) (2006) 398.

[14] J. B. SOUZA, Tese (Dourado) Escola de Engenharia de São Carlos (2006).

[15] S. ROSSI, M. ANTONELLI, V. MEZZANOFTE, C. NARIZZO, Water Environ. Res. 79 (4) (2007) 341. [16] A. JOLIVET-GOUGEON, A. S. BRAUX, F. SAUVAGER, M. ARTURO-SCHAAN, M. CORMIER, Can. J. Microbiol. 42 (1996) 60.

[17] L. LIBERTI, M. NOTARNICOLA, Wat. Sci. Technol. 40 (1999) 235.

[18] J. B. BRASILEIRO, J. L. COLODETTE, D. PILÓ-VELOSO, Quím. Nova 24 (6) (2001).

[19] V. LAZAROVA, M. L. JANEX, L. FIKSDAL, C. OBERG, I. BARCINA, Wat. Sci. Tech. 38 (12) (1998) 109.

[20] D. FALSANISI, R. GEHR, L. LIBERTI, M. NOTARNICOLA, Water Qual. Res. J. Can. 43 (1) (2008) 47.

[21] S. STAMPI, G. DE LUCA, M. ONORATO, E. AMBROGIANI, F. ZANETTI, J. App. Microbiol. 93 (2002) 725.

[22] A. ASLARI, C. ROQUES, G. MICHEL, Can. J. Microbiol. 38, (1992) 635. 